\title{
Identifying current training provision and future training needs in allergy available for UK general practice trainees: national cross-sectional survey of General Practitioner Specialist Training programme directors
}

\author{
Jayne Ellis', Imran Rafi', Helen Smith ${ }^{3},{ }^{*}$ Aziz Sheikh ${ }^{4}$ \\ Academic FY2 in General Practice, St George's Healthcare NHS Trust, London, UK \\ 2 Director, Clinical Innovation and Research Centre, Royal College of General Practitioners, London, UK \\ ${ }^{3}$ Professor of Primary Care, Division of Primary Care and Public Health, Brighton and Sussex Medical School, Brighton, UK \\ ${ }^{4}$ Professor of Primary Care Research and Development, Allergy and Respiratory Research Group, Centre for Population Health Sciences, \\ The University of Edinburgh, Edinburgh, UK
}

Received 6th June 2012; revised 23rd July 2012; accepted 2nd August 2012; online 17th October 2012 xx

\begin{abstract}
Background: There are ongoing concerns about the quality of care provision for allergy in primary care.

Aims: To identify current training provision in allergy to GP trainees and to understand how this could be enhanced.

Methods: A cross-sectional survey of GP Speciality Training (GPST) programme directors was undertaken. Programme directors of the 174 GPST schemes were sent an online questionnaire which was informed by the content of the Royal College of General Practitioners curriculum. Quantitative data were descriptively analysed and a thematic analysis was undertaken of free text responses.

Results: We obtained responses from 146 directors representing 106 training programmes. Responses indicated that two-thirds (62\%, 95\% $\mathrm{CI} 53.1$ to 71.5 ) of programmes were providing at least some allergy training, with the remaining third stating that they either provided no training or were unsure. Overall, one-third $(33 \%, 95 \% \mathrm{Cl} 22.7$ to 42.2$)$ of programme directors believed that all the relevant allergy-related curriculum requirements were being met. Where provided, this training was believed to be best for organ-specific allergic disorders but was thought to be poorer for systemic allergic disorders, particularly food allergy where $67 \%(95 \% \mathrm{Cl} 57.5$ to 76.5$)$ of respondents indicated that training was poor. There was considerable interest in increasing the allergy training provided, preferably through eLearning modules and problem-based learning materials supported by those with relevant specialist knowledge.

Conclusions: This UK-wide survey has identified important gaps in the training of GP trainees in relation to allergy care. Addressing these gaps, particularly in the management of systemic allergic disorders, should help to improve delivery of primary care-based allergy care.

(C) 2013 Primary Care Respiratory Society UK. All rights reserved.

J Ellis et al. Prim Care Respir J 2013; 22(1): 19-22

http://dx.doi.org/10.4104/pcrj.2012.00087
\end{abstract}

Keywords allergy, cross-sectional survey, GP trainees, primary care

See linked editorial by Papadopoulos and Savvatianos on pg 5

\section{Introduction}

The prevalence of allergic diseases increased dramatically over the second half of the 20th century ${ }^{1}$ and it is now estimated that one in three of the UK adult population is diagnosed with an allergic condition at some point in their lives. ${ }^{2,3}$ In children in the UK this proportion increases to around $50 \% .{ }^{4}$ In parallel with this sharp increase in prevalence there has been an accompanying increase in disease severity, ${ }^{1}$ particularly in those with more systemic allergic disorders. In the UK the diagnosis and management of patients with allergic diseases takes place predominantly within primary care, ${ }^{1}$ where it now comprises a significant proportion of the primary care workload. ${ }^{2}$

Concerns regarding the quality of care provided to allergy sufferers have been highlighted in a number of reports. In their 2003 report "Allergy: The Unmet Need", the Royal College of Physicians reported that the National Health Service (NHS) is failing to achieve even the most minimal standards of care for allergy. ${ }^{1}$ These findings

* Corresponding author: Professor Aziz Sheikh, Primary Care Research and Development, Allergy and Respiratory Research Group, Centre for Population Health Sciences, The University of Edinburgh, Teviot Place, Edinburgh EH8 9DX, UK. E-mail: aziz.sheikh@ed.ac.uk 
were echoed by reports from the House of Lords in 2006, ${ }^{5}$ the Scottish Medical and Scientific Advisory Committee in 2009, ${ }^{6}$ the World Allergy Organization in 2006, and a further report from the Royal College of Physicians "Allergy Services: Still not Meeting the Unmet Need" ${ }^{8}$ There is therefore a recognised need for improved service delivery in both primary and secondary care.

Reasons underpinning poor allergy care within the NHS are multifactorial including shortages of allergy specialists and the related paucity of allergy education in the UK medical undergraduate curriculum. Concerns have also repeatedly been raised about the lack of allergy knowledge - particularly in relation to diagnostic testing and the management of systemic allergic problems such as food allergy - and the limited training opportunities for primary healthcare professionals. ${ }^{5}$ In 2004 a national survey of general practitioners (GPs) found that only half of those sampled had received any training in allergy. ${ }^{9}$ Since then, a number of UK government reports have highlighted the need for improvement in allergy training for primary healthcare professionals. Despite this, a 2009 follow-up survey supported by the Royal College of General Practitioners (RCGP) reported that only $29 \%$ of responding GPs had received any formal allergy training. ${ }^{10}$

Under the auspices of the RCGP, we conducted a nationwide survey of General Practice Speciality Training (GPST) programme directors to identify current training needs and opportunities in allergy available for GP trainees. The survey was informed by the contents of the RCGP curriculum which identifies a number of core competencies relating to the diagnosis and care of patients with allergic problems. We also wanted to identify good practice in allergy training and to understand the support that GPST training programmes may require to expand allergy education for their trainees.

\section{Methods}

\section{Ethical considerations}

The survey did not involve any patient involvement and therefore ethical permission was not sought. The programme directors were fully informed and participated voluntarily with their responses kept confidential and anonymous.

\section{Study design, sampling and data collection}

A cross-sectional internet-based survey of programme directors representing all 174 GPST programmes in the UK was conducted. We obtained a database of all GPST programmes from the National Recruitment Office for GP Training website; email addresses of the programme directors were obtained from the central deanery offices.

The questionnaire was developed in consultation with GPST programme directors, GPs, and GP academics. It was designed around the core competencies in allergy highlighted in the RCGP curriculum. ${ }^{11}$ The design of the survey drew upon a questionnaire that had been used in two earlier cross-sectional primary care studies enquiring about allergy care. ${ }^{9,10}$ The survey was piloted prior to use with local GPST programme directors. The programme directors were asked to respond to the questions with respect to the teaching delivered from August 2010 to July 2011.

To optimise response rates, three follow-up emails were sent over a 3-month period. Only the first response from each training programme was used. Responses were collected between October 2011 and January 2012.

\section{Data analysis}

Descriptive statistics were used to summarise the main findings with 95\% confidence intervals (Cl) for proportions; Microsoft Excel 2010 was used for analysis. Where programme directors were asked to rate the quality of the allergy training currently being delivered using

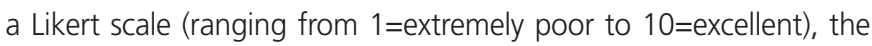
mean and standard deviation (SD) of all responses for a given topic were calculated. The number and proportion of programme directors rating the quality of the training as $1-5$ on the Likert scale was also calculated and, as in previous work, ${ }^{9,10}$ was interpreted as signifying a 'poor' rating. Thematic analysis of the free text data was undertaken.

\section{Results}

Responses were obtained from 146 programme directors representing 106/174 (61\%) GPST programmes. Not all respondents responded to every question in the survey; in these instances the working denominator is stated in each results section.

\section{Delivery of allergy training}

$62.3 \%$ (66/106; $95 \% \mathrm{Cl} 53.1$ to 71.5 ) of training programmes that responded to the survey were currently providing allergy education for their trainees. The remaining $30.2 \%(32 / 106 ; 95 \% \mathrm{Cl} 21.5$ to 38.9) reported either not providing any allergy education or being unsure $(7.5 \%(8 / 106 ; 95 \% \mathrm{Cl} 2.5$ to 12.5$))$. This training was delivered in a variety of settings including 'half-day release teaching sessions led by dermatologists and ear nose and throat specialists', 'paediatric study afternoons', 'teaching from a local allergy consultant', 'anaphylaxis training from A\&E staff' and as 'part of Basic Life Support training'. A number of programme directors noted statements to the effect that 'there is no formal training; training will come in their general practice experience'.

\section{Quality of training}

Table 1 summarises the views of the programme directors on the quality of training provided in relation to the diagnosis and treatment of the most common allergic conditions encountered in primary care and, in addition, the more generic issue of when to refer for a specialist assessment. This shows that, overall, programme directors were of the view that organ-specific allergic disorders (i.e. eczema, allergic rhinitis/conjunctivitis, and asthma) were better taught than the more systemic allergic disorders (i.e. angio-oedema, urticaria and, in particular, food allergy). However, anaphylaxis was thought to be well taught by the majority of respondents. About half of the programme directors thought that teaching on when to refer to an allergy specialist was poor.

\section{Proportion of training schemes meeting curriculum requirements and perceived need to improve allergy education}

$33 \%$ (33/99; 95\% Cl 22.7 to 42.2) either strongly agreed or agreed that the training being provided was meeting all curriculum requirements, 26\% (26/99; $95 \% \mathrm{Cl} 17.4$ to 34.6$)$ either strongly disagreed or disagreed, and the remaining $40 \%$ were unsure (40/99; $95 \% \mathrm{Cl} 30.4$ to 49.7$)$.

The majority (65\%) of programme directors (63/97; $95 \%$ Cl 55.5 
Table 1. General Practitioner Specialist Training programme directors' opinions on the quality of training with respect to core allergy competencies measured on a 10-point Likert scale

\begin{tabular}{|c|c|c|}
\hline Competency & Mean (SD) & Rated poor (scores 1-5) n $(\%, 95 \% \mathrm{Cl})$ \\
\hline${ }^{*}$ Acute management of anaphylaxis: diagnosis & $7.1(2.12)$ & $19 / 96(20 \%, 95 \% \mathrm{Cl} 12$ to 28$)$ \\
\hline${ }^{\star}$ Acute management of anaphylaxis: treatment & $7.1(2.08)$ & $18 / 95(19 \%, 95 \% \mathrm{Cl} 11$ to 27$)$ \\
\hline *Allergic conjunctivitis: diagnosis & $6.7(2.07)$ & $27 / 97(28 \%, 95 \% \mathrm{Cl} 19$ to 37$)$ \\
\hline *Allergic conjunctivitis: treatment & $6.7(2.08)$ & $26 / 96(27 \%, 95 \%$ Cl 18 to 36$)$ \\
\hline *Allergic rhinitis: diagnosis & $6.7(1.82)$ & $23 / 98(23 \%, 95 \% \mathrm{Cl} 15$ to 31$)$ \\
\hline *Allergic rhinitis: treatment & $6.7(1.83)$ & $24 / 98(24 \%, 95 \% \mathrm{Cl} 16$ to 32$)$ \\
\hline *Angio-oedema: diagnosis & $5.5(2.36)$ & $44 / 96(46 \%, 95 \% \mathrm{Cl} 36$ to 56$)$ \\
\hline *Angio-oedema: treatment & $5.6(2.31)$ & $41 / 94(44 \%, 95 \% \mathrm{Cl} 34$ to 54$)$ \\
\hline *Asthma: diagnosis & $7.4(1.88)$ & $14 / 97(14 \%, 95 \% \mathrm{Cl} 7$ to 21$)$ \\
\hline *Asthma: treatment & $7.4(1.78)$ & $11 / 97(11 \%, 95 \% \mathrm{Cl} 5$ to 17$)$ \\
\hline *Atopic eczema: diagnosis & $7.3(1.56)$ & $14 / 98(14 \%, 95 \% \mathrm{Cl} 7$ to 21$)$ \\
\hline *Atopic eczema: treatment & $7.3(1.54)$ & $13 / 98(13 \%, 95 \%$ Cl 6 to 20$)$ \\
\hline Food allergy: diagnosis & $4.6(2.31)$ & $64 / 95(67 \%, 95 \% \mathrm{Cl} 58$ to 76$)$ \\
\hline Food allergy: treatment & $4.5(2.30)$ & $64 / 95(67 \%, 95 \% \mathrm{Cl} 58$ to 76$)$ \\
\hline Urticaria: diagnosis & $6.4(2.06)$ & $27 / 95(28 \%, 95 \% \mathrm{Cl} 19$ to 37$)$ \\
\hline Urticaria: treatment & $6.3(2.14)$ & $31 / 95(33 \%, 95 \% \mathrm{Cl} 24$ to 42$)$ \\
\hline When to refer to an allergy specialist & $5.2(2.50)$ & $49 / 96(51 \%, 95 \% \mathrm{Cl} 41$ to 61$)$ \\
\hline
\end{tabular}

to 74.5) were of the opinion that their trainees would benefit from more allergy training, with only a small minority (9\%) expressing a contrary view (9/97; 95\% Cl 3.3 to 14.7). The remaining 26\% (25/97; $95 \% \mathrm{Cl} 17.3$ to 34.7$)$ had no definite view on this issue.

Of the $33 \%$ (33/99) of programme directors who either strongly agreed or agreed that the training delivered was meeting all curriculum requirements, 45\% (15/33) also strongly agreed or agreed that their trainees would benefit from more training.

\section{Approaches to enhancing training provision}

Table 2 summarises the ways in which programme directors would prefer to enhance the allergy training provided. There was particular interest in the availability of elearning programmes and the opportunity for problem-based learning, and greater access to those with relevant allergy expertise who could help deliver training.

\section{Discussion}

\section{Main findings}

The results of this survey suggest that the majority $(62.3 \% ; 95 \% \mathrm{Cl}$ 53.1 to 71.5 ) of GPST programmes in the UK report that their programmes provide at least some form of allergy education. Given the high prevalence of allergic problems and the long-recognised care concerns centring on primary care, $2,4,5,9,10$ the fact that one-third of responding GPSTs appear not to be providing any training is a matter of concern. Even where training was being provided, there was considerable variation in the perceived quality of allergy training between clinical topics. For example, the majority of programme directors felt that that diagnosis of atopic eczema and asthma was well taught but only a minority were of the opinion that the same was true for food allergy. Moreover, the majority of programme directors (65\%; 95\% Cl 55.5 to 74.5$)$ strongly agreed or agreed that their trainees would benefit from more training in allergy. Allergy eLearning programmes, problem-based learning sessions, and improved accessibility to tutors with expertise in allergy were all highlighted as being the most convenient strategies for enabling programmes to expand the allergy training they deliver.

\section{Strengths and limitations of this study}

This is, as far as we are aware, the first time that a survey of GP allergy training provision has ever been undertaken. The main strengths of this study are the efforts to ensure that the survey design was robust by drawing on an instrument that has been used in two previous national cross-sectional primary care studies, ${ }^{9,10}$ the assurances of confidentiality to respondents, and the wide geographical coverage achieved. The fact that the survey was structured around the core competencies in allergy as highlighted by the RCGP curriculum provided structure and credibility."

The main limitations of this work include the fact that not all programme directors responded despite being sent a number of reminders. It also needs to be borne in mind that we sought opinion about the contents and quality of training which, whilst having the potential to offer important insights, may not necessarily correspond

Table 2. Preferred approaches to enhancing allergy training for GP trainees

\begin{tabular}{ll} 
Examples of training options & $\begin{array}{l}\mathrm{n}(\%, 95 \% \mathrm{Cl}) \text { strongly agree or agree that training tool would be } \\
\text { beneficial in supporting GPST programmes to expand allergy education }\end{array}$ \\
\hline eLearning programmes & $90 / 104(87 \%, 95 \% \mathrm{Cl} 81$ to 94$)$ \\
\hline Problem-based learning sessions & $84 / 102(82 \%, 95 \% \mathrm{Cl} 75$ to 90$)$ \\
\hline Improved accessibility to tutors with expertise in allergy & $73 / 103(69 \%, 95 \% \mathrm{Cl} 60$ to 78$)$ \\
\hline Increase in time for centralised teaching & $36 / 101(36 \%, 95 \% \mathrm{Cl} 27$ to 45$)$ \\
\hline Lecture notes & $39 / 103(38 \%, 95 \% \mathrm{Cl} 29$ to 47$)$ \\
\hline GPST=General Practitioner Specialist Training. &
\end{tabular}


with the training that is actually delivered or received by trainees. ${ }^{12,13}$ Interpretation of findings in relation to previously published work

Although the paucity of postgraduate education in allergy has been noted, there has been no work done to date to quantify this gap in GPST programmes. In comparison with a UK survey of GPs performed in 2009 which found that only $29 \%$ of GPs surveyed had received allergy training ${ }^{10}$ the results of this study suggest that the current cohort of trainees may be receiving more training in allergy. More generally, the concerns about the perceived management of systemic allergic reaction - particularly food allergy - echo the findings of the earlier GP surveys, ${ }^{9,10}$ highlighting the fact that training centred on these disorders is likely to be perceived as useful by both GP trainees and more established GPs. The recent publications of national guidelines on food allergy and anaphylaxis by the National Institute for Health and Clinical Excellence (NICE) ${ }^{14,15}$ and anaphylaxis guidelines by the World Allergy Organization ${ }^{16,17}$ should create a further impetus for improved training in these important clinical areas.

\section{Implications for future research, policy and practice}

The results from this study suggest that, although the majority of training programmes are delivering at least some allergy education, the majority of programme directors are of the opinion that this should be enhanced. This conclusion is in line with a number of UK government reports ${ }^{5,6}$ highlighting the need for improvement in allergy training for primary healthcare professionals. The results of this study support the development of a range of teaching materials to support GPST programmes in expanding their allergy education. Future work should also extend the tools enquired about to include apps for the increasingly ubiquitous smartphones and tablets. In view of the variation in the perceived quality of training between topics, it is important that these teaching materials initially focus upon clinical areas such as food allergy and criteria for specialist referral where programme directors believe there is a major deficiency in the current training. It is also important that trainees are taught about the comprehensive assessment of patients with involvement of multiple organ systems. Once delivered, there is a need to establish whether such training is perceived as useful by those being trained and, importantly, whether this then translates into the much needed improvements in care provision for people with allergic problems. ${ }^{18,19}$ Conclusions

This UK-wide survey has identified important gaps in the training of GP trainees in relation to allergy care. Addressing these gaps, particularly in the management of systemic allergic disorders, should help to improve delivery of primary care-based allergy care.

\section{Handling editor Mohammed Osman Yusuf Statistical review Gopal Netuveli}

Acknowledgements We are grateful to colleagues in the Clinical Innovation and Research Centre for their help with undertaking this work and to the programme directors for their time.

Conflicts of interest AS and HS are the RCGP's Clinical Champions for Allergy. IR is the Medical Director of the RCGP Clinical Innovation and Research Centre. AS is Joint Editor-in-Chief of the $P C R J$ and but was not involved in the editorial review of, nor the decision to publish, this article.

Contributorship AS conceived the idea for this study and oversaw all aspects of its execution and writing. JE undertook the survey and led the writing under the supervision of IR. HS contributed to the design of the study and writing.

Funding None.

\section{References}

1. Royal College of Physicians. Allergy: the unmet need. A report of the Royal College of Physicians Working Party on the provision of allergy services in the UK. 2003.

2. Gupta R, Sheikh A, Strachan DP, Anderson HR. The burden of allergic disease in the UK. Unpublished study commissioned by the British Society for Allergy and Clinical Immunology, London, 2002

3. Anandan C, Gupta R, Simpson CR, Fischbacher C, Sheikh A. Epidemiology and disease burden from allergic disease in Scotland: analyses of national databases. $J R$ Soc Med 2009;102(10):431-42. http://dx.doi.org/10.1258/jrsm.2009.090027

4. Punekar YS, Sheikh A. Establishing the incidence and prevalence of cliniciandiagnosed allergic conditions in children and adolescents using routinely collected data from general practices. Clin Exp Allergy 2009;39(8):1209-16. http://dx.doi.org/10.1111/j.1365-2222.2009.03248.x

5. House of Lords Select Committee on Science and Technology. Chapter 9: Allergy Services. http://www.publications.parliament.uk/pa/ld200607/ldselect/ldsctech/ 166/16612.htm (accessed 16 May 2012)

6. Review of Allergy Services in Scotland: A Report by a Working Group of the Scottish Medical and Scientific Advisory Committee, 2009. http://www.scotland.gov.uk/ Publications/2009/06/17135245/17 (accessed 16 May 2012)

7. Warner J, Kaliner M, Crisci C, et al. Allergy Practice Worldwide: A report by the World Allergy Organisation Speciality and Training Council. Int Arch Allergy Immunol 2006;139(2):166-74. http://dx.doi.org/10.1159/000090502

8. Royal College of Physicians and Royal College of Pathologists Working Party. Allergy services: still not meeting the unmet need. 2010. http://bookshop.rcplondon.ac.uk/contents/pub317-44f79458-267d-4006-af053f0e468e22c5.pdf (accessed 16 May 2012)

9. Levy M, Price D, Zheng X, Simpson C, Hannaford P, Sheikh A. Inadequacies in UK primary care allergy services: national survey of current provisions and perceptions of need. Clin Exp Allergy 2004;34:518-19. http://dx.doi.org/10.1111/j.13652222.2004.1945.x

10. Hazeldine M, Worth A, Levy M, Sheikh A. Follow-up survey of general practitioners' perceptions of UK allergy services. Prim Care Respir J 2010;19(1):84-6. http://dx.doi.org/10.4104/pcrj.2010.00002

11. Royal College of General Practitioners. Curriculum statements. 2010 http://www.rcgp-curriculum.org.uk/rcgp_-_gp_curriculum_documents/ gp_curriculum_statements.aspx (accessed 16 May 2012) http://dx.doi.org/10.1142/S2010194512008495

12. Shehata $Y$, Ross $M$, Sheikh A. Undergraduate allergy teaching in a UK medical school: mapping and assessment of an undergraduate curriculum. Prim Care Respir 2006;15(3):173-8. http://dx.doi.org/10.1016/j.pcrj.2006.04.002

13. Shehata $Y$, Ross $M$, Sheikh A. Undergraduate allergy teaching in a UK medical school: comparison of the described and delivered curriculum. Prim Care Respir 2007;16(1):16-21. http://dx.doi.org/10.3132/pcrj.2007.00004

14. NICE. Food allergy in children and young people: diagnosis and assessment of food allergy in children and young people in primary care and community settings. http://www.nice.org.uk/nicemedia/live/13348/53214/53214.pdf (accessed 23 July 2012)

15. NICE. Anaphylaxis: assessment to confirm an anaphylactic episode and the decision to refer after emergency treatment for a suspected anaphylactic episode. http:// www.nice.org.uk/nicemedia/live/13626/57537/57537.pdf (accessed 23 July 2012)

16. Simons FE, Ardusso LR, Bilò MB, et al. World Allergy Organization anaphylaxis guidelines: summary. J Allergy Clin Immunol 2011;127(3):587-93.e1-22.

17. Simons FE, Ardusso LR, Bilò MB, et al. 2012 Update: World Allergy Organization guidelines for the assessment and management of anaphylaxis. Curr Opin Allergy Clin Immuno/ 2012;12(4):389-99. http://dx.doi.org/10.1097/ACl. 0b013e328355b7e4

18. Sheikh A, Khan-Wasti S, Price D, Smeeth L, Fletcher M, Walker S. Standardized training for healthcare professionals and its impact on patients with perennial rhinitis: a multi-centre randomized controlled trial. Clin Exp Allergy 2007;37(1):90-9. http://dx.doi.org/10.1111/j.1365-2222.2006.02619.x

19. Hammersley VS, Walker S, Elton R, Sheikh A. Protocol for the adolescent hayfever trial: cluster randomised controlled trial of an educational intervention for healthcare professionals for the management of school-age children with hayfever. Trials 2010;11:84. http://dx.doi.org/10.1186/1745-6215-11-84 